\title{
An Empirical Study of E-Commerce and its Significant Impact in Business
}

\author{
Industries \\ Tan Yeow Chong Larry \\ University of Mississippi, USA \\ E-Mail: ytan1@olemiss.edu
}

\begin{abstract}
In this research article the researcher emphasized that significant role and impact of E-commerce in Business Industries. The researcher focused on analysis of significant factors of E-commerce, positive and genitive impact of E-commerce, and challenges of E-Commerce in Business Industries. The researcher defines the dimension of E-commerce with respect to business to business (B2B) and business to consumer (B2C) towards the changing way of doing business on the web in Business Industries. The main objectives of this research article is to focus on the primary route by which e-commerce will affect the economy at large is through its impact on productivity and inflation. Businesses and consumers that use E-commerce benefit from a reduction in costs in terms of the time and effort required to search for goods and services and to complete transactions of business activities which are carried out electronically on the Internet rather than at a physical location.
\end{abstract}

Keywords : E-commerce, B2B, B2C, Business Industries

\section{INTRODUCTION}

E-commerce businesses are fast gaining grounds and changing the way of merchants doing business. The main aspect of E-commerce involves doing business on the web and includes [1]:

1. Business to business (B2B) trading which involves a business such as a company trading with another business on the World Wide Web.

2. Business to consumer (B2C) trading which involves a business such as a company directly dealing with consumers over the World Wide Web.

Through websites and portal, some businesses do business with other businesses, an e-commerce model known as B2B. Other businesses sell to consumers online, in a B2C e-commerce model. E-commerce has made it easier for businesses to reach a much wider audience at much lesser expense than what a traditional retail operation will require. With an Ecommerce setup, there is no requirement to acquire expensive shopfront in prime areas or for that matter any physical area. A merchant can also produce or store his goods at a remote, cheaper storage location and while being able to market and sell it worldwide. While the cost of developing a good website may be substantial, it is still much cheaper than renting or buying expensive storefronts in the 'high street' by comparison. Additionally, once the merchant website is operational, it can potentially reach a wide client base. The merchant will then have to focus on cost effective product order fulfilment and timely delivery [2] [3].

\section{Why E-Commerce?}

Traditional retail companies that have made significant investments in developing physical retail infrastructures are suddenly finding themselves being 
outran by smaller e-commerce startups with much lesser physical infrastructure. These E-commerce based startups typically ship order goods out via overseas suppliers who produce high-quality goods at lower cost. This gives the startups an advantage over vertically integrated companies that have traditionally sought to do everything from production to supply. It should be noted that these monolithic companies understandably can't be the best in everything; instead, a company may be good in one aspect and another in a different aspect. The traditional companies are therefore being forced to focus only on what they can do best and outsource the rest if they want to compete favorably [4] [5].

The E-commerce model has contradicted the classic economic theory of decreasing returns scale which holds that a business cannot grow its profits infinitely due to physical expansion considerations. Ecommerce based enterprises have been shown to be able sustain fast growth while increasing returns as well. The reason is that these startups have minimal infrastructure and inventory and instead leverage on information and communication [5]. In fact, industries dealing in information based product, can literally bring the cost per unit distribution and sale to zero via E-commerce [6].

E-commerce has radically changed the way people make purchase decisions. With changes in the purchase habits, it's only right that advertising tactics also vary accordingly. Today, even consumers who shop traditionally at a brick and mortar store, look up products information online, read other users' reviews and compare prices before they make the decision to purchase. Businesses today no longer can depend on traditional marketing techniques alone [8]. The researcher must consider digital marketing (including mobile) to meet the demands of the techsavvy consumers of today. Search engine optimization, paid ads, email marketing, social media engagements are some of the tactics that business owners employ to reach out to millions of potential customers online [9].

\section{RELATED WORK}

Behshid Behkamal et.al.,(2006) proposed a comprehensive investigation of effective factors on success of B2B electronic commerce that are under control of SMEs themselves These variables include individual features of companies and environment have no influence on them. In this paper basic components are divided into four primary gatherings; business infrastructure, $\mathrm{HR}$, client interface and technical infrastructure. Additionally in our methodology, factors were viewed from SMEs viewpoints [1].Vinamra Nayak, Nitin Jain(2012) emphasized on Use of e-commerce arrangements will help enterprises to expand their business through broader item exposure, better customer service, accurate order entry processes and faster item fulfillment [2].

Sokolov Mladenović, S., and Ćuzović, Đorđe. (2016). Focused on development of e-commerce has influenced its implementation in the travel industry where it is observed like an instrument for improving the efficiency of business activities. However [3]. Niranjanamurthy M, ,Dr. Dharmendra Chadha(2012) emphasized that the increase of the demand, flexibility and power of wireless deals provides proper opportunities for ascending services to customers. Indeed, this could mean the real services giving in all times. In the current Business associations, mobile commerce or M-Commerce has been entered in finance, services, retails, and telecommunication and data technology services. In these sectors, M-Commerce isn't just being widely accepted yet additionally it is being more used as a prominent method for business/commerce [4]. 
Lipsa Sadath (2013) emphasized that information is considered as an essential type of data that needs collection, management, mining and interpretation to create knowledge. Modern e-commerce is likewise enthusiastically developing that makes resources and services on the internet lavishly bright. Businesses targeting customers has a direct connect with the economy of a nation as the current e-commerce system is used by people from layman to business tycoons [5]

Dr. Singh Sohan, Prof. (Dr.) Sharma R. K.(2010) stated that internet has brought to the universe of business e-commerce and it refers to use of computer networks for purchasing and selling merchandise, data and services. It integrates E-Mail, Electronic Fund Transfer (EFT), Electronic Data Interchange (EDI) and comparative techniques into a comprehensive electronic system of exchanging. Ecommerce combines IT, Telecommunication technology and business process to make it feasible to work together in manners that couldn't be even idea of earlier. It opens up new avenues of exchanging and improves efficiency and effectiveness of conventional business processes, markets and services [6].

Sameeah Alvi (2016) focused on M-commerce is the subsequent generation of e-commerce which facilitates the user to access internet without requiring a place for module. Today, mobile isn't merely used for sending messages or for calling however it serves a wide variety of other purposes that are beneficial in corporate world. M-commerce helps in improving relationship with customers. It is an area that is still under development phase and offers potential prospects for further research and applications. Since the subject is at the stage of progress, this research help explore how and why mcommerce is increasing consistent prevalence and assuming control over e-commerce and initiates further research on the reasons of development of $\mathrm{m}$ commerce expertise. Earlier studies suggest that e- commerce and $\mathrm{m}$-commerce are not just leading edge for doing worldwide business and trade yet in addition offers multiple benefits to the business, government and consumers on generous scale. [7].

María de la Soledad Zapata Agüera (2009) focused on utilizing computerized channels that enables you to transcend customary requirements such a geography and time zones to connect with an a lot wider audience. For this creator, e-marketing is significant because the market is worldwide and wider, and it is necessary to be able to reach a segment with precision utilizing the computerized marketing that gives us this choice [8].

Vera Pujani, Refdinal Nazir (2019) emphasized those E-commerce applications that play in different stages of the environmental effect especially energy utilizations. The internet technology and electronic commerce (e-commerce) which drastically changed the trend of data system (IS) applications in business to be internetworked e-business will be reviewed. The commitment of e-commerce on business has been identified as one of success variables to pick up companies targets. In line with data technology development, e-commerce is likewise more used by business associations around the globe. The use of ecommerce has the effect on environmental effects in terms of energy utilizations [9].

Amol Kale, Rajivkumar Mente (2018) identifies the services and utilizations of M-commerce. In Mobile Commerce purchasing and selling of merchandise and ventures utilizing mobiles which are wireless handled device. Mobile commerce is the next generation of E-commerce which enable costumer to access internet from anywhere. Current days, mobile are not use just for sending test message or calling however it likewise used for other facilities, for example, web perusing. This network technology used in M-commerce based on wireless application convention. It helps in improving relationship with customer [10]. 
Dr. Shahid Amin Bhat (2016) stated that E-commerce is a blast in the modern business which defines $\mathrm{E}$ commerce means electronic commerce. E-commerce (Electronic commerce) involves purchasing and selling of merchandise and enterprises, or the transmitting of assets or information, over an electronic network, predominantly the Internet. Ecommerce (Electronic commerce) is a change in outlook influencing the two marketers and the customers [11].

Dr Kishore Kumar Das (2015) emphasized that factors that are fuelling development in E-Commerce sector in Business World. The methodology of my examination is from secondary sources, for example, articles, diaries, reports, papers ,sites and conference proceeding . E-Commerce one of the highest developing business, with India having great market potential for investments. There has been huge surge in investment since a year ago and more is expected in coming years. The fast development being used of mobile and internet users has facilitated E-Commerce business in both urban and country cities [12].

Rajneesh Shahjee (2019) focused on investigation of the effect of Electronic Commerce on Business. The research study has highlighted the Management Information Systems, Finance and Accounting, Marketing and Computer Sciences of E-Commerce on Business. E-commerce is a method for leading business over the Internet. In spite of the fact that it is a relatively new concept, it can possibly alter the conventional type of economic activities [13].

Dr. Rajasekar S. also, Sweta Agarwal (2016) stated that E-commerce involves an online exchange. Ecommerce provides multiple benefits to the consumers in type of accessibility of merchandise at lower cost, wider choice and saves time. The general category of E-Commerce can be broken down into two sections: E-Merchandise and E-finance. Numerous companies, associations, and communities in India are working together utilizing E-commerce and furthermore are receiving $\mathrm{M}$-commerce for working together [14].

Anuj et.al. (2018) emphasized that the importance of E-Commerce in Indian economy. It is very much imperative to have government intervention and huge investment inflow in type of foreign direct investment in large economy like India to stabilize and increase the development of E-Commerce industry in the economy. In this paper the researcher will look towards the role of government in ECommerce industry and furthermore look towards the different barriers of e commerce in Indian aspects. "In this research paper the researcher discussed for the most part about B2C E-Commerce and its percentage of total national output in Indian economy [15].

Shahriari et.al. (2015) emphasized that many economists and experts believe that in recent years, a revolution has occurred like the mechanical revolution which the world has entered the data age. It makes large changes in the economic, social and social aspects. One aspect of this change is changes in economic relations between people, companies and governments. Commercial exchange between people who had been based on paper documents to exchanges of by us the systems based on electronic data. In this article the researcher examined the benefits of e-commerce and its effect on the market [16].

Rajendra Madhukar Sarode (2019) emphasized that E-commerce is one of the business alternatives that one should explore in the future. E-Commerce is said to achieve change in perspective on the planet for exchanging. Prediction e-commerce is indicating tremendous business development in our nation. Backed by increased online user base and mobile phone presentation, Indian e-commerce has seen impressive development over the most recent couple of years. Considering India's demographic dividend 
and rising internet accessibility, the sector is slated to scale greater heights [17].

Madhurima Khosla, Harish Kumar (2017) stated that $\mathrm{E}$-commerce is one of the fastest developing segments to encourage and support the development of $\mathrm{E}$ Commerce. The survival of the e-commerce firms in a profoundly unique environment becomes a challenging errand when coupled with the relentless competition prevailing in the sector [18].

\section{OBJECTIVES OF THE STUDY}

The researcher stated that E- commerce is playing one of the significant role in business Industries to control the business activities and transaction with rapid and convenient way in between business to business (B2 B) and business to consumer (B2C). In this research article the researcher focused on some of the significant research issues:

1. Analysis the factors of E-commerce which are significant in Business Industries.

2. Analysis the positive and negative impact of E-Commerce in Business Industries.

3. To study the challenges of $\mathrm{E}$ - commerce in Business Industries.

\section{RESEARCH METHODOLOGY}

This research paper has been written on the basis of secondary data. The secondary data were collected from published books, journals, research papers, magazines, daily newspaper, internet and official statistical documents. The study is qualitative in nature.

\section{SIGNIFICANT IMPACT OF E-COMMERCE IN BUSINESS INDUSTRIES}

The researcher emphasized that E-commerce offers businesses a vital opportunity to offer their customers round-the-clock convenience [11]. A good ECommerce strategy that adds excellent customer service and a dynamic social media presence into the mix can spell higher traffic and better sales for your business. E-commerce and the never-ending array of virtual companies are today challenging longaccepted economic practices and creating hypercompetition like never before. While globalization and the internet open up newer markets for you to reach out to, it brings you a hoard of competitors who are all waiting to steal your market share[12].In this era of digitalization and online shopping, businesses that don't jump on the e-commerce bandwagon are bound to get lost in the melee. That doesn't mean you have to reach out to the first Ecommerce website design services you come across to design an online shopping portal for your company[14][15].

1. Return on Intangibles: Traditionally, while intangible assets helped businesses remain competitive in their field, other physical assets like building, equipment, IT infrastructure, proper management (HR), and customer relations helped companies to gain an edge over their competitors. With the growth in the internet and widespread availability of E-commerce, today businesses are able to make profits out of their intangible assets. Today, collaboration and communications between suppliers and vendors is easier and cost next to nothing. This means businesses can now leverage their intangible assets to a broader market. E-Commerce has removed all time and space constraints that businesses faced just a few years ago. Companies no longer have to work in a particular geographical location or time zone.

2. Low Cost of Initial Business Setup: Just a few decades back, to set up a business, one will require massive capital costs. However, E-commerce changed all this. Today, thanks to the internet, it is completely possible to set up a global company 'out of one's garage' with minimal investments.

3. Bigger Market Exposure: Traditionally, small business owners who specialized in a particular niche were restricted to very specific markets. Even though 
their niche was customized and distinct, they couldn't make higher profits due to the inability to reach out to bigger markets.

4. Elimination of Middlemen: Today, businesses can directly sell to customers without the need for any intermediaries or middlemen. For example, a local fabric merchant who previously have to depend on a network of vendors and brokers to distribute his / her fabrics to selected geographical locations can now expand beyond his / her confined vicinity by himself / herself.

5. Businesses are now Open $24 \times$ 7: In the world of Ecommerce there is no downtime. Businesses are opened for $24 \times$ 7, 365 days of the year. And, sales can happen at any time of the day, every day. Traditionally, businesses had to close shop at the end of the day, in whichever location they are in. This means shoppers were restricted and had to complete their purchases within a particular time.

\section{The Size of the Company No longer Matters:}

Whether we run your online business solo-handed or with the help of a hundred-member team, it makes no difference to the end consumer. This means as mentioned before, a small business owner can compete on a level playing field with the large players in the market.

Traditionally, small business owners faced major drawbacks due to their lack of staff. They couldn't match the customer service provided by massive brick and mortar stores. Today, the situation has altered. The positives of running a small business far outweigh big, clunky corporations in the online world, thanks to AI chat bots and various Ecommerce automations [17].

\section{POSITIVE AND NEGATIVE IMPACT OF E- COMMERECE IN BUSINESS INDUSTRIES}

Since E-commerce is a business activity carried out electronically on the Internet rather than at a physical location, comes with its own set of challenges. The advent of e-commerce has brought about both positive and negative effects.

1. Lost of Privacy: Retailers with an ecommerce presence can collect a lot of information about visitors to their websites. By setting up electronic trackers in the buyers' browser cache called cookies that track the surfing patterns of visitors, ecommerce merchants can collect the shopping profiles and preference of their online customers. This allows the former to target advertisements to the latter based on what is relevant and recent. While it may be used to enhance shoppers' shopping experience, some critics argues that this activity intrudes on consumers' privacy.

2. Security Threats: While offering convenience to both sellers and buyers, the negative effect of e-commerce is its potential threat to the security of consumers' personal information. When consumers buy online, they typically input their credit card number and other personal information. Hackers can access this information through security flaws in the merchant's computer system. Merchants have since become much more vigilant about information security than they were in the early days of e-commerce.

3. Reduced Carbon Footprint: One positive effect of the emergence of e-commerce is that it may save energy. Consumers who shop online rather than drive to stores use lesser fuel and their cars emit less pollution. Also, because e-commerce reduces the need for warehouse space to house goods near retail stores, these warehouses use less energy. On the flip side, the usage of electricity has 
increase to house data servers as well has power the millions of computers used in the transaction.

4. Cost Reduction: E-commerce can reduce costs for consumers when companies cut down on middlemen involved in distributing goods, warehouse space to store the goods and personnel overheads. E-commerce also enables companies to manage their inventory better through connected management systems. To be competitive, businesses are likely to pass down at least some of these savings to consumers.

5. Lower Profit Margins: With the information efficiency comes transparency of price. Merchant can no longer mark up their profits excessively for the reasons the buyer has many other choices with lower prices. The seller will need to constantly compete for higher positive user ratings and greater volume to make the same amount of profits.

\section{CHALLENGES OF E-COMMERCE IN BUSINESS INDUSTRIES}

Any E-Commerce businessperson knows very well, the level of competition for E-commerce customers has likewise never been higher. As indicated by numerous industry experts, there are at any rate four dimensions to the challenges confronting ECommerce in the present crowded online marketplace. The real challenges of E-commerce include:

1. Economic Challenges: The economic challenges confronting E-Commerce merchants include the costs related to establishing an E-commerce business, the number of competing online merchants, issues connected with infrastructure upgrades, and the accessibility (or shortage) of skilled staff. It is estimated up to 90 percent of the Internet have are from the high-income countries which make up just about 16 percent of the world's population. The opportunity and also challenge is how to bridge the larger parts of the physical world who are not tech savvy or ready to embrace the Internet, let alone e-commerce.

2. Technological Challenges: As indicated by industry observers, the essential technologyrelated challenges confronting E-commerce businesses include security concerns, transfer speed accessibility, and integration with existing conventions. Integrating Internet software with existing applications and databases presents an ongoing technology challenge. Another challenge resulting from increased E-commerce activity is constantly developing the reliability of network infrastructure to cope with the growing usage demand.

3. Security: One of the realities of the explosive prevalence of E-commerce is that it has become an attractive target for digital hoodlums; cyber cheating; cyber scams. With each new prominent 'hacking' incident, consumer confidence in online retailing takes a 'hit' which further raises the awareness and concerns of E-commerce security. E-Commerce technology is constantly evolving and integrating that new security measures is by no means an easy or inexpensive endeavor.

4. Social Challenges: In recent years, consumers' concern over issues, for personal data protection, and the sharing of personal data has escalated exponentially. Furthermore, there are social differences that has come into play when growing an E-commerce business beyond its 
native region. Unlike conventional merchants who were easily able to use their familiar language and marketing methods that went well with their targeted local audience, online sellers now have to take into consideration the numerous semantic, social and social differences in their extended customer base. Any of those differences can possibly create hindrances for Ecommerce companies in their efforts to develop long haul 'relationships' with an expansive customer base.

5. Legal Challenges: In spite of the fact that it might seem just as E-commerce has been in existence for a very prolonged stretch of time, the reality is that it is still at its infancy with numerous unresolved legal issues, including those pertaining to intellectual and technological property rights. Then there are legal issues pertaining to tax assessment: as noted in our previous cites and covered extensively in business media in recent months. For example, the recent Supreme Court's decision enabling various states to impose online sales taxes on businesses that are not physically located inside their boundaries can possibly drastically affect the profitability of Ecommerce companies nationwide. The decision to charge nonresident E-commerce operators is a setback to one of the prime drivers of $\mathrm{E}$ Commerce for their phenomenal success; which is the ability to earn globally without being restrained by the local taxation laws, leading a huge drawback for E-commerce companies to increasing market share in some countries.

\section{CHALLENGES FACING E-COMMERCE}

A recent analysis of the E-commerce identified several trends that will likely help to shape the future of online sales. Some of the most significant ecommerce trends shaping its future include [12] [13]:
1. Online to Offline Growth: Despite explosive growth in recent years, E-commerce still represents only about 11.9 percent of retail sales, although that is up from only 3.5 percent a decade ago. As a result, "online to offline" commerce is a trend to watch, as merchants strive to provide "shoppers with a digital experience that can match a distinctive in-store feel."

2. Multi-Channel E-commerce: Mobile customers are expected to account for $\$ 319$ billion in sales by 2020, and "multi-channel" sales, providing customers the ability to easily purchase goods through an array of avenues, will become evermore important in the years ahead, going forward, successful online merchants will need to have an infrastructure that manages and maintains a seamless multi-channel retailing experience.

3. E-commerce Automation: As technology continues to evolve, so do the operational needs of online merchants. In addition to fulfillment automation in the warehouse, ensuring that a business' website is fully up-to-date with the latest technology, requiring minimal human involvement on a daily basis, will be vital to continued success for e-commerce companies.

4. Mobile E-commerce's Growing Popularity: According to data from Adobe, in 2017 on both Black Friday and Cyber Monday of that year, 30 percent of online sales closed through mobile devices. Although desktop is still far more popular for making ecommerce purchases, mobile is growing in popularity and should no longer be seen as just a method of allowing online customers to 'browse and buy'. The challenge would be how to push the envelope of presenting the most intuitive and engaging experience in a 6-inch screen real estate.

5. Opportunities in International E-commerce: The study found that 1.4 billion people will join the 
global 'middle class' by 2020, with 85 percent of that growth in the Asia Pacific region. Establishing local partnerships, familiarizing oneself with regional laws and customs, and ensuring strong, effective marketing will all be key elements to consider as ecommerce companies consider expanding into the global ecommerce market.

Although we are still less than two decades into the new century, many E-commerce merchants are already facing the challenges of 'growing pains'moving beyond their start-up phase, and trying to optimize the opportunities that come with growth and business maturation.

\section{CONCLUSION}

In this research paper, the researcher emphasized that E-commerce has rapidly changed the way in which businesses operate. The researcher also stated the significant impact of E-commerce in Business Industries with respect to business-to-business (B2B) and business-to-consumer (B2C) are the technology enabled innovations like digital payments, hyperlocal logistics, analytics driven customer engagement and digital advertisements will likely support the growth in the sector. The growth in E-commerce has a significant impact on business Industries towards boost employment, increase revenues from export, increase tax collection by ex-chequers, and provided better products and services to customers intelligently using collected big data. Finally the researcher concluded that E-commerce has grown rapidly and changed significantly over the years, as such there is plenty of various factors for buyers, investors and entrepreneurs to be mindful of. The researcher analyzed the significant drivers which are directly related to E-commerce and its usage in business Industries and also stated that positive, negative impact in the business Industries.

\section{REFERENCES}

[1]. Behshid Behkamal, Mohammad Kazem Akbari, Mohsen Kahani (2006).Critical Success Factors For Success Of,B2b Electronic Commerce In SMES,IADIS International Conference eCommerce 2006, Information Technology at Amirkabir University of Technology.

[2]. Vinamra Nayak, Nitin Jain(2012).Proceedings of the Second International Conference on Soft Computing for Problem Solving (SocProS 2012), December 28-30, 2012 pp 507-517.

[3]. Sokolov Mladenović, S., and Ćuzović, Đorđe. (2016). the Role of E-Commerce in Tourism Development of the Republic of Serbia. TISC Tourism International Scientific Conference Vrnjačka Banja, 1(2), 518-535.

[4]. Niranjanamurthy M, Dr. Dharmendra Chahar (2012). E-Commerce and M-Commerce: Issues and Recommended Screening, International Journal of Marketing and Technology, IJMT Volume 2, Issue 8 ISSN: 2249-1058

[5]. Lipsa Sadath (2013).Data Mining in ECommerce: A CRM Platform, International Journal of Computer Applications (0975 - 8887), Volume 68-No.24, April 2013.

[6]. Dr. Singh Sohan, Prof. (Dr.) Sharma R. K.(2010). Business research in e-commerce: challenges and strategy, Mangalmay Journal of Management and Technology, Year: 2010, Volume: 4, Issue: 2, Print ISSN: 0973-7251. Online ISSN: 2230-729X.

[7]. Sameeah Alvi (2016).Running Head: Intention to Adopt M-Commerce over E-Commerce, KASBIT Business Journal (KBJ) Vol. 9, 154-175, December, 2016.

[8]. María de la Soledad Zapata Agüera (2009). Understanding E-Marketing Strategies, 
Handbook of Research on Entrepreneurship and Marketing for Global Reach in the Digital Economy, 2019 |Pages: 35 , DOI: 10.4018/978-15225-6307-5.ch017.

[9]. Vera Pujani, Refdinal Nazir (2019).E-Commerce Impacts on Energy Consumptions: A Conceptual Framework: Management Department, Andalas University

[10]. Amol Kale, Rajivkumar Mente(2018).MCommerce: Services and applications, International Journal of Advanced Science and Research, Volume 3; Special Issue 1; March 2018; Page No. 19-21, ISSN: 2455-4227.

[11]. Dr. Shahid Amin Bhat (2016).A Review Paper on E-Commerce, TIMS 2016-International Conference, At Gwalior, February 2016,ITM University Gwalior.

[12]. Growth of E-Commerce in India, International Journal Of Core Engineering and Management (IJCEM) Volume 2, Issue 4, July 2015 25, ISSN: 23489510.

[13]. Rajneesh Shahjee(2019).The Impact Of Electronic Commerce On Business Organization, Scholarly diary for interdisciplinary research, ISSN:2278-8808

[14]. Dr. Rajasekar S. also, Sweta Agarwal (2016).A Study on Impact of E-Commerce on India's Commerce, International Journal of Development Research Vol. 6, Issue, 03, pp. 7253-7256, March, 2016.

[15].Anuj, Fahad Fayaz, Ms Namita Kapoor (2018).Impact of E-Commerce in Indian Economy, IOSR Journal of Business and Management (IOSR-JBM) e-ISSN: 2278-487X, pISSN: 2319-7668. Volume 20, Issue 5. Ver. VI. (May. 2018), PP 59-71.

[16]. Shahrzad Shahriar, Mohammadreza Shahriari, Saeid gheiji(2015).E-Commerce and It Impacts On Global Trend and Market, University College of Commerce \&Business Management
Osmania University, Hyderabad, Vol.3(Iss.4):April,2015] ISSN-2350-0530(O) ISSN-2394-3629(P).

[17]. Rajendra Madhukar Sarode (2019).Future of ECommerce in India Challenges and Opportunities, International diary of applied research, ISSN Print: 2394-7500 ISSN Online: 2394-586.

[18]. Madhurima Khosla, Harish Kumar (2017).Growth of E-commerce in India: An Analytical Review of Literature, IOSR Journal of Business and Management (IOSR-JBM), Volume 19, Issue 6. Ver. I (June 2017), PP 91-95, e-ISSN: 2278-487X, p-ISSN: 2319-7668.

\section{Cite this article as :}

Tan Yeow Chong Larry, "An Empirical Study of ECommerce and its Significant Impact in Business Industries", International Journal of Scientific Research in Science and Technology (IJSRST), Online ISSN : 2395-602X, Print ISSN : 2395-6011, Volume 6 Issue 5, pp. 75-84, September-October 2019. Available at

doi : https://doi.org/10.32628/IJSRST196510 Journal URL : http://ijsrst.com/IJSRST196510 